\title{
Predicting recurrence of depression using lifelog data: an explanatory feasibility study with a panel VAR approach
}

\author{
Narimasa Kumagai ${ }^{1}$, Aran Tajika ${ }^{2^{*}}$ (D), Akio Hasegawa ${ }^{3}$, Nao Kawanishi ${ }^{4}$, Masaru Horikoshi ${ }^{5}$, Shinji Shimodera ${ }^{6,7}$, \\ Ken'ichi Kurata ${ }^{8}$, Bun Chino ${ }^{9}$ and Toshi A. Furukawa ${ }^{7}$
}

\begin{abstract}
Background: Although depression has a high rate of recurrence, no prior studies have established a method that could identify the warning signs of its recurrence.

Methods: We collected digital data consisting of individual activity records such as location or mobility information (lifelog data) from 89 patients who were on maintenance therapy for depression for a year, using a smartphone application and a wearable device. We assessed depression and its recurrence using both the Kessler Psychological Distress Scale (K6) and the Patient Health Questionnaire-9.

Results: A panel vector autoregressive analysis indicated that long sleep time was a important risk factor for the recurrence of depression. Long sleep predicted the recurrence of depression after 3 weeks.
\end{abstract}

Conclusions: The panel vector autoregressive approach can identify the warning signs of depression recurrence; however, the convenient sampling of the present cohort may limit the scope towards drawing a generalised conclusion.

Keywords: Depression, Kessler psychological distress scale, Kurashi-app, Lifelog, Long sleep time, Panel vector autoregressive model, Patient health Questionnaire-9

\section{Background}

Depression has a high rate of recurrence. Epidemiological and clinical evidence suggests that major depressive disorder typically follows a recurrent course, with a third to half of the patients relapsing within 1 year of discontinuation of treatment [1]. The greater the number of prior depressive episodes, the higher is the probability of a future recurrence $[2,3]$. Therefore, it is very important to identify the warning signs of recurrence early in order to prevent it.

A large number of studies have investigated the environmental factors that predict depression recurrence. Social support including marriage may reduce the recurrence risk [4], and women are more vulnerable to depression recurrence in midlife [5, 6]. However, factors such as educational attainment, socioeconomic status, life events, and number

\footnotetext{
* Correspondence: aran.tajika28@gmail.com

${ }^{2}$ Department of Psychiatry, Kyoto University Hospital, 54

Shogoin-Kawahara-cho, Sakyo-ku, Kyoto 606-8507, Japan

Full list of author information is available at the end of the article
}

of children have shown no significant association with depression recurrence [6]. Key lifestyle factors that may predict recurrence are still poorly understood. One study involving healthy individuals found that a more irregular social rhythm — not going to bed or eating meals at a similar time every day-was predictive of dismal mental health [7]. In recent years, it has become easier to obtain lifelog data from smartphones and wearable devices. Lifelog refers to digital data of individual activity records such as location information or mobility information. Nevertheless, no study has investigated the relationship between depression recurrence and the daily activities of patients in remission.

Statistical analysis is often laden with ambiguities when investigating the relationship between mental health status and lifestyle factors (e.g., sleeping habits). Cox proportional-hazards models are commonly used when examining time to recurrence $[2,4,8-10]$ or when testing for moderation of maintenance-treatment effects on recurrence [11]. However, survival analysis using Cox proportional-hazards models cannot take into account

(c) The Author(s). 2019 Open Access This article is distributed under the terms of the Creative Commons Attribution 4.0 International License (http://creativecommons.org/licenses/by/4.0/), which permits unrestricted use, distribution, and 
the bidirectional relationships between lifestyle factors and poor mental health status. For example, insomnia can increase depression risk and vice versa [12]. On one hand, the value of weekly Kessler Psychological Distress Scale (K6) in the current period is likely to correlate with its value in the previous period; whereas on the other hand, bidirectional causal relationships between weekly $\mathrm{K} 6$ and its closely related variables might be discovered. The changes in lifestyle can be seen as the predictors of future recurrence of depression, or as precursors that are early signs of depression recurrence. The estimation function should include two aspects of predictors and precursors, regardless of whether true roles are independent predictors or not.

Therefore, multivariate regression such as vector autoregressive (VAR) models must be used when analysing possible risk factors of depression recurrence. The VAR models fit each dependent variable on past lags of itself.

In the present study, we examined whether the change of activity record on weekly basis calculated from lifelog data collected via smartphone and a wearable device, such as time spent sleeping, exposure to ultraviolet (UV) light, number of meals, etc., could predict the recurrence of depression among patients with major depression remission. We estimated panel VAR (PVAR) models considering both directions of the relationship between risk factors of recurrence and poor mental health status.

This manuscript is organised as follows. Section 2 outlines the characteristics of the data collected through lifelogging applications via a smartphone app and a wearable device. In this section, the variables of interest and the empirical methods are described. Section 3 reports the estimation results of the PVAR models. Section 4 discusses the specificity of this study. Finally, Section 5 contains the conclusions.

\section{Methods}

This study explored the dynamic interdependencies between poor mental health status and lifestyle factors. We used PVAR models that have lags of all endogenous variables and analysed the weekly interdependencies among variables of interest.

\section{Procedures}

We used a smartphone (iPhone, Apple inc.) app called Kurashi-app ("kurashi" means "life" in Japanese) and a wearable device (Silmee W20, TDK Co. Ltd., Japan) to collect lifelog data from 89 patients who had suffered from major depression, but were then in remission. We collected the activity diaries of the patients over a period of 1 year.

There are some advantages of having patients record their activity diaries via a smartphone. First, it is easier for patients to record their activity, regardless of time and place, compared to the conventional method of pen and paper. Secondly, utilizing the lifelogs, patients can record their activity diaries more easily. The Kurashiapp collects individual's lifelogs via smartphone and estimates their activities based on them. It predicts 16 types of activities from lifelog data of location information, mobility information, and steps information and displays them on screen. The patients are expected to check them every day, and when the prediction is incorrect, they can rectify it. Consequently, the precision of the prediction improves. The recordings of the 16 activities on Kurashi-app can therefore be regarded as semiautomated self-reports. The system is expected to increase precision and to reduce burden on the part of the participants. When being presented with their estimated activities, users can be helped to record activity diaries even when they cannot distinctly remember certain activities from their daily lives [13].

The Kurashi-app includes 16 kinds of activities: meeting friends or family, bath/shower, childcare/caregiving, commuting, domestic work, exercise, hospital, meal, shopping, sitting idly, sleep, study/work, hobby/entertainment/learning, TV/DVD/game/music, reading/newspaper/magazine, and other activities. These 16 activities were selected from the classification of the Basic Survey on Social Life (Shakai seikatsu kihon chosa) by the Statistics Bureau of the Ministry of Internal Affairs and Communications in Japan. Sitting idly is included because "time spending vaguely without doing anything in particular" is considered important with regard to poor mental health status. The Kurashi-app extracts clusters of activities where patients stay for more than $30 \mathrm{~min}$ at a time.

Simee W20 is a wrist watch type wearable device which can collect UV data automatically, in addition to location and mobility information.

We collected the activity diaries of each patient for 1 year. Outpatients were recruited at four university hospitals and their associated hospitals and clinics. Kyoto University was the central secretariat, and the 4 university hospitals were Kochi University, Hiroshima University, Nagoya City University, and Toho University. We recruited a hundred patients in total into the study between October 2016 and March 2017. Ten patients withdrew themselves from the study; while one patient did not meet the inclusion criteria and was therefore excluded. Inclusion criteria were as follows: (1) age between 22 and 69 years; (2) meet DSM-5 criteria for major depressive disorder, recurrent; (3) in remission as defined by the Beck Depression Inventory-II score of 9 or less [14]; (4) with or without anxiety disorder or dysthymia; (5) able to use a mobile phone; (6) able and willing to participate in the study. We excluded patients with bipolar disorder, substance use disorder, psychosis, and personality disorder. 
We used two screening and diagnostic tools to assess depression, K6 and the Patient Health Questionnaire-9 (PHQ-9). Using the Kurashi-app, patients completed the $\mathrm{K} 6$ by themselves once a week. However, such recordings are prone to lapses because they rely on self-reports on the smartphone. At the doctor's consultation every 4 weeks, clinical study coordinators of Kyoto University assessed the patients through the PHQ-9 on the telephone. When the patients failed to visit the doctor, we contacted them by telephone to make the monthly assessments with PHQ-9 in order to minimise carelessness.

The $\mathrm{K} 6$ is a six-item screening instrument assessing psychological distress developed by Kessler and his colleagues [15]. Respondents rated how frequently they had experienced the following six symptoms over the past 7 days: a) feeling nervous, b) feeling hopeless, c) feeling restless or fidgety, d) feeling depressed to the point that nothing could cheer you up, e) feeling everything was an effort, and f) feeling worthless. Respondents rated each item using a 5-point scale: 0 ("none of the time"), 1 ("a little of the time"), 2 ("some of the time"), 3 ("most of the time"), or 4 ("all of the time"). Responses to the six items were summed to yield a $\mathrm{K} 6$ score between 0 and 24 , with higher scores indicating a greater tendency towards mental illness. Using the receiver operating characteristic curve, Prochaska et al. [16] identified a K6 score $\geq 5$ as the optimal cut-off point indicative of moderate mental distress. The coefficient of correlation between $\mathrm{K} 6$ and the Hamilton Depression Rating Scale was 0.516 at the $1 \%$ significant level [17].

The PHQ-9 questionnaire asks respondents how frequently they have experienced the following nine symptoms over the past 2 weeks: a) having little interest or pleasure in doing things, b) feeling depressed or hopeless, c) having trouble staying asleep or sleeping too much, d) feeling tired, e) having poor appetite or overeating, f) feeling bad about oneself, g) having trouble concentrating on things, h) moving or speaking so slowly that other people could have noticed, i) having thoughts that you would be better off dead. Respondents rated each item using a 4-point scale: 0 ("not at all"), 1 ("several days"), 2 ("more than half the days"), or 3 ("nearly every day"). The PHQ-9 is commonly used to screen for depression with 10 as the cut-off score; a score of 10-14 indicates moderate depression, 15-19 moderately severe depression, and 20-27 severe depression. We have slightly modified the time frame for PHQ-9 in this study and asked the participants to rate their symptoms during the worst two weeks of the past month, in order to increase sensitivity to detect a depressed episode between the monthly assessments. The item responses on the PHQ-9 exhibited the same mathematical pattern as the other depression screening scales such as K6 and the Center for Epidemiological Studies Depression Scale [18].

Daily chart of the 16 activities were visualised on the Kurashi-app, and all participants could check the data themselves at any time. The data from wearable device could be checked by connecting the device to their iPhone (this task was voluntary).

Since participants experienced some recurrence of depression, their motivations to know the sign of recurrence was high. We paid 5000 JPY (= about 47 USD) per month to the participants for 1 year. About half of the participants had their own iPhone and downloaded the app. To the remaining half, we lent our study iPhones, which were returned after the follow up period. We also lent wearable devices to all participants. The patients were expected to don the wearable device except when they bathed. We also accepted it when some patients preferred not to wear it while asleep. All data obtained from the app and wearable device were uploaded to the database server at Kyoto University. We monitored the adherence of the participants and reminded them when the adherence dropped during their monthly visits to the clinics/hospitals.

\section{Collected data}

We analysed the data of $\mathrm{K} 6$ score in order to observe weekly change of mood. Because $\mathrm{K} 6$ is a self-reported questionnaire on the smartphone, some participants forgot to enter their responses on the Kurashi-app weekly. When K6 data is missing, the lagged variables of the PVAR models do not show real-time differences. In order to avoid this problem, the researchers must supplement missing data. Assuming that data is missing at random (MAR), to supplement missing $\mathrm{K} 6$ data, we used the PHQ-9 score as an explanatory variable of the multiple regression equation. Daily missing data was not associated with the recurrence of depression, and we used its imputed series for weekly data series.

When dealing with MAR data, we can consider that the probability distribution of missing data is independent of that of non-observational data. We conducted Little's CDM (covariate-dependent missingness) test [19] as a special case of MAR. The CDM test gave a $p$-value 0.102 and the hypothesis that the variables of interest are MCAR (missing completely at random) were not rejected at the 5\% significance level. Therefore, the estimate is biased when one ignores the missing data [20]. We corrected this bias by estimating the regression equation using auxiliary variables. A previous study showed that the use of many auxiliary variables may contribute to satisfy the premise of MAR [21].

The regression equation approach may underestimate the standard deviation of the true value. However, Stata (ver. 15) cannot run PVAR models after multiple 
imputations. We thus estimated the multiple regression equation and imputed missing variables. The long length of activity diaries may increase the number of recurrence episodes over the sample period. Considering this, researchers must pay attention to heteroskedasticity problems. We used the number of weeks from entry in the study as the analytic weight of the regression equation. This variable is inversely proportional to the variance of observations. Lifelog data were aggregated by the week. Explanatory variables of the regression equation to impute K6 data were as follows: PHQ-9 score, mean of sleep hours during the past week, long sleep time, short sleep time, gender, educational attainment, occupational status, and marital status.

We selected the variables of the PVAR models as follows. The first candidate variables were enough time spent sleeping and exposure to UV light. These are good lifestyle factors recommended by Sarris et al. [12]. The second candidate variables were selected using a twosample t-test for difference of means. The homogeneity of variance was assumed. The two-sample t-test (the sample was divided between those with long sleep time/ short sleep time and without) showed differences for five variables: meal, sitting idly, study/work, domestic work, and exercise. Finally, we calculated the correlation coefficient between $\mathrm{K} 6$ scores and these five activity variables, and selected two as explanatory variables of the PVAR models. The correlation coefficients of the two variables with $\mathrm{K} 6$ scores were 0.229 for sitting idly and 0.199 for the number of times lunch was not eaten.

The UV light exposure data were collected every minute by a wearable device Silmee W20. We defined a missing UV light value when collected data was below $80 \%$ of $1440 \mathrm{~min}$ (1152 min). Major reasons for missing out on UV light data were depleting battery life or restrained donning of the wearing device because of periodic irritation. Considering the differences in eating habits, we calculated a standardised variable of the number of times lunch was not eaten and used it as an explanatory variable of the PVAR models. We used standardised variables in order to accommodate patient heterogeneity that may account for large portion of total variances of key variables when using non-standardised variables. Since the standard deviation of the number of times lunch was not eaten was a large value of 2.46 , we considered that the raw variable did not capture the differences in eating habits. Like the procedure for K6 scores, we imputed missing values of UV light and the standardised variable of the number of times lunch was not eaten.

\section{PVAR model}

As a key dependent variable of weekly $\mathrm{K} 6$, we considered a 5-variate PVAR of order $\mathrm{p}$ with panel-specific fixed effects represented by the following system of linear equations:

$$
\begin{aligned}
& Y_{i t=} Y_{i t-1} A_{1}+Y_{i t-2} A_{2}+\cdots+Y_{i t-p} A_{p}+X_{i t} B \\
& \quad+v_{i t}+e_{i t}
\end{aligned}
$$

where $Y_{i t}$ is a $(1 \times 5)$ vector of dependent variables; $X_{i t}$ is a $(1 \times \mathrm{q})$ vector of exogenous covariates; $v_{i t}$ and $e_{i t}$ are $(1 \times 5)$ vectors of dependent variable-specific fixedeffects and idiosyncratic errors, respectively. The $(5 \times 5)$ matrices $A_{1}, A_{2}, \ldots, A_{p}$ and the $(\mathrm{q} \times 5)$ matrix $B$ are parameters to be estimated.

With the presence of lagged dependent variables in the right-hand side of the system of equations, estimates would be biased even with a large $N$ [22]. Fixed-effects estimation tends to underrate the predictions of the coefficient of the lagged dependent variables. Taking these problems into consideration, following the procedure of Michael-Abrigo and Love [23], we used unbalanced panel data and estimated PVAR models by fitting a multivariate panel regression of each dependent variable on lags of itself and on exogenous variables. The estimation was done using the generalised method of moments (GMM). Because the presence of a unit root will invalidate the GMM specification, the estimates of the PVAR model must satisfy the stability condition. If all the eigenvalues lie inside the unit circle, the stability condition of the PVAR model is satisfied and the PVAR model is invertible.

We specified the PVAR model as follows. First, using the overall coefficient of determination $(\mathrm{CD})$, we specified the maximum lag order to be included in the PVAR model. As explained below in section 3.1, the PVAR model consisted of five dependent variables as follows: the natural logarithm of $\{(\mathrm{K} 6+1) /$ square root of the number of episodes\}, dummy variable of long sleep time or short sleep time, standardised variable of the number of times lunch was not eaten, natural logarithm of standardised variable of UV light, and dummy variable of sitting idly. Because the K6 repeated with relatively high frequency may cause respondent's "learning curve" reaction, we used the square root of the number of previous episodes to control for each patient's past experiences of depression. All the patients suffered from recurrent depression and those with increased numbers of previous episodes tended to report, on average, higher K6 scores. In order to balance the sensitivity of K6 scores across the subjects with variable number of previous episodes, we divided their natural logarithm of $(\mathrm{K} 6+1)$ scores by the square root of their number of previous episodes.

Second, we confirmed the stability condition of the estimated PVAR model. Third, based on the value of CD shown in Table 1, we decided that the maximum lag 
Table 1 Maximum lag order of PVAR

\begin{tabular}{ll}
\hline Number of participants $=87$ & \\
\hline Average number of weeks $=41.95$ & CD \\
\hline Lag & 0.98562 \\
1 & 0.98827 \\
2 & 0.98933 \\
3 & 0.98972 \\
4 & 0.98762 \\
5 & 0.96484 \\
6 &
\end{tabular}

$C D$ coefficient of determination, $T$ Observations per panel

order was 4. The CD captures the proportion of variation explained by the PVAR model as follows:

$\mathrm{CD}=1$-(determinant of covariance matrix of idiosyncratic errors/determinant of unconstrained covariance matrix of the dependent variables).

\section{Results}

\section{Patient characteristics and PVAR variables}

Initially we recruited 100 patients, but one patient was found not to have met the inclusion criteria at baseline and was therefore excluded. Of the 99 remaining patients, 10 dropped out. The reasons were as follows: too burdensome $(n=6)$, house relocation $(n=2)$, recovered $(\mathrm{n}=1)$, and lost to follow up $(n=1)$. While $92 \%$ of activity diaries during the sample period were recorded, the patients corrected one third of estimated activities by the Kurashi-app. Table 2 shows the characteristics of patients at the baseline and the variables of the PVAR models are shown in Table 3. The mean age of patients at the time of entry was 44.3 years; $74 \%$ of patients had received education after high school graduation. The largest proportion had regular employment (54\%), followed by inactive persons (16\%) and part-time workers (13\%). Married persons accounted for $54 \%$ of the sample, followed by those who never married (33\%) and divorced persons $(12 \%)$. The mean age at the first depression episode was 34.9 years. The mean time period from the first episode was 9.4 years. The mean number of depression episodes was 2.5. The correlation between the time from the first depression episode and the number of episodes was significant at the $1 \%$ level. The correlation coefficient was 0.38 for women and 0.33 for men.

It is well known that there is a positive relationship between sleep disorders and depression [24]. Taking this relationship into account, we defined dummy variables of both long sleep time and short sleep time. Hours of sleep were considered the total hours slept from noon of the previous day to noon of the current day. The dummy variable of long sleep time took the value of 1 when the number of hours of sleep was higher than the sum of mean hours of sleep over the past 7 days and its
Table 2 Characteristics of patients

\begin{tabular}{ll}
\hline Variables & Number (\%) or Mean (SD) \\
\hline Gender (Male) & $49(55.1)$ \\
Age & $44.3(10.8)$ \\
Educational background & \\
Junior high school & $3(3.4)$ \\
High school & $20(22.5)$ \\
University, etc. & $66(74.2)$ \\
Occupational status & \\
Regular worker & $48(53.9)$ \\
Part-time worker & $12(13.5)$ \\
Leave & $3(3.4)$ \\
Homemaker & $6(6.7)$ \\
Retired & $3(3.4)$ \\
Inactive & $14(15.7)$ \\
Other & $3(3.4)$ \\
Marital status & \\
Never married & $29(32.6)$ \\
Divorced & $11(12.4)$ \\
Widowed & $1(1.1)$ \\
Married & $48(53.9)$ \\
First depression episode & \\
Age at first episode & $34.9(11.6)$ \\
Years from first episode & $9.4(5.8)$ \\
Number of episodes & $2.5(1.7)$ \\
\hline N=89 & \\
\hline
\end{tabular}

$N=89$

standard deviation. In contrast, the dummy variable of short sleep time took the value of 1 when the number of hours of sleep was lower than the difference between the mean hours of sleep over the past 7 days and its standard deviation. Long sleep and short sleep were defined according to the sleep time which participants had selfreported on Kurashi-app.

\section{Estimation results}

We excluded two patients whose K6 scores were extremely high through the study period, and thus used 87 samples (Average Observations per panel $=44.33$ weeks) for the PVAR model estimation (Fig. 1). Because invariant variables such as educational attainment are excluded when estimating PVAR models, we used a seasonal dummy variable and a pseudo-positive dummy variable as exogenous variables. The seasonal dummy variable took the value of 1 if the month during the study period was December or January, and 0 otherwise. The pseudo-positive dummy variable took the value of 1 if $\mathrm{K} 6$ score $>9$ and PHQ-9 score $<5$. It means a false alarm of recurrence of depression. The prevalence of pseudo-positive was $0.3 \%$ (17/4863). 
Table 3 Dependent variables of panel vector autoregressive (PVAR) models

\begin{tabular}{|c|c|c|c|c|c|}
\hline Variables & $N$ & Mean & SD & Min & $\operatorname{Max}$ \\
\hline K6 & 4830 & 4.19 & 4.35 & 0.0 & 24.0 \\
\hline Natural logarithm of $(\mathrm{K} 6+1)$ & 4830 & 1.30 & 0.87 & 0.0 & 3.22 \\
\hline \multicolumn{6}{|l|}{ Daily sleep hours during the past week } \\
\hline Mean & 4476 & 7.99 & 1.61 & 0.9 & 20.1 \\
\hline SD & 4401 & 1.48 & 1.05 & 0 & 8.5 \\
\hline Coefficient of variation & 4401 & 0.19 & 0.14 & 0 & 2.6 \\
\hline Dummy variable for long sleep & 4863 & 0.04 & 0.19 & 0 & 1 \\
\hline Dummy variable for short sleep & 4863 & 0.04 & 0.21 & 0 & 1 \\
\hline Daily hours sitting idly during the past week & 4501 & 1.13 & 1.43 & 0 & 14.5 \\
\hline Daily UV light during the past week & 4840 & 16.47 & 16.66 & 0 & 136.6 \\
\hline Number of days of not eating lunch & 4863 & 2.48 & 2.46 & 0 & 7 \\
\hline
\end{tabular}

The PVAR model using the whole sample, which included five dependent variables and four lags, satisfied the stability condition. The estimated coefficient indicated that 3-week lagged long sleep increased the K6 score in the present week. Results of Model I $(N=87)$ indicated that long sleep time in patients predicted the recurrence of depression after 3 weeks (Table 4). The estimated coefficient of this week-lagged long sleep was 0.172. This implies that long sleep time increased the K6 score from 5 to 6.126 after 3 weeks. Model I had positive lagged effects of long sleep on K6 and not eating lunch, and negative lagged effects of $\mathrm{K} 6$ on not eating lunch (not shown in Table 4).

The prevalence of long sleep time was about $6 \%$ in the patients aged $50-59$ years, while it was almost $3 \%$ in the other age groups. Patients aged $50-59$ years had a higher regular employee ratio (72.2\%), and the proportion of regular employees in the other age groups was $50.3 \%$. Because there was an intergenerational difference in both the prevalence of long sleep time and regular employee ratio, we used sub-samples. We estimated two
PVAR models: (II) sample excluding patients aged 5059 years $(N=69)$ and (III) patients aged $50-59$ years $(N=18)$.

Model II with a pseudo-positive dummy variable consisted of five dependent variables, which satisfied the stability condition (lags $=4, C D=0.987953$ ). On the other hand, model III without a pseudo-positive dummy variable consisted of four dependent variables, which satisfied the stability condition (lags $=4, C D=0.994561$ ). A pseudo-positive dummy variable was not significant in model III.

Tables 5 and 6 show the estimation results of models II and III. We found that long sleep time was an important risk factor for the recurrence of depression. Model II excluding patients aged 50-59 years suggested two aspects of long sleep time as a strong predictor of depression recurrence. First, we found a replicated effect including positive lagged effects of long sleep on $K 6$ and not eating lunch, and negative lagged effects of K6 on long sleep and not eating lunch. Secondly, long sleep time was a superior predictor of depression recurrence,

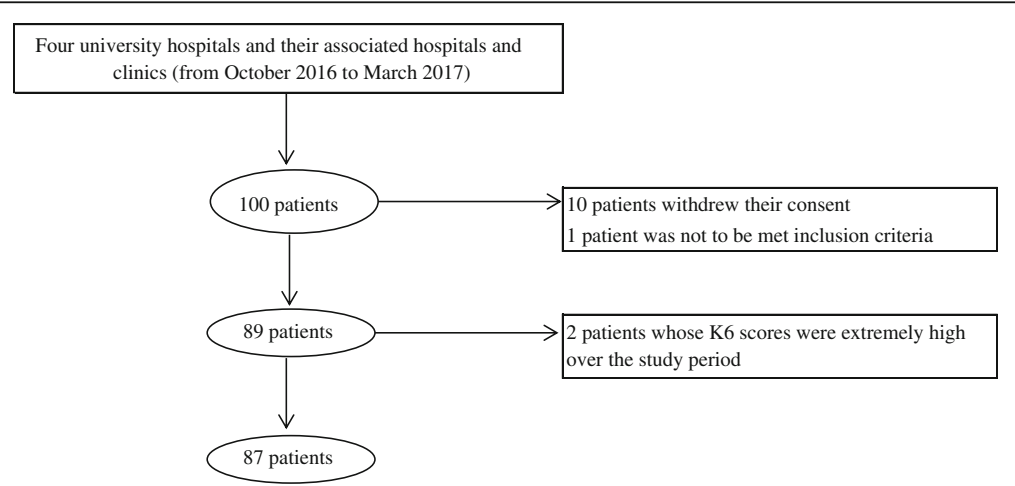

Fig. 1 Flow chart of recruited patients. Note: Inclusion criteria are as follows: (1) Age between 22 and 69 years; meet DSM-5 criteria for major depressive disorder recurrent episode; (3) Beck Depression Inventory-II score 0-9 (which means remission); (4) with or without anxiety disorder or dysthymia; (5) able to use mobile phone; (6) able and willing to participate in the study 
Table 4 PVAR model I $(N=3857)$

\begin{tabular}{|c|c|c|c|c|c|}
\hline Selected variables & $\begin{array}{l}\text { Natural log of }\{(K 6+1) / \text { square root of the } \\
\text { number of episodes }\}\end{array}$ & $\begin{array}{l}\text { Number of times not eating lunch } \\
\text { (standardized) }\end{array}$ & $\begin{array}{l}\text { Natural log of } \\
\text { UV light }\end{array}$ & $\begin{array}{l}\text { Long } \\
\text { sleep }\end{array}$ & $\begin{array}{l}\text { Sitting } \\
\text { idly }\end{array}$ \\
\hline \multirow[t]{2}{*}{ Not eating lunch $(-1)$} & 0.0117 & $0.338^{* * *}$ & 0.00208 & -0.0385 & 0.0864 \\
\hline & $(0.0431)$ & $(0.0430)$ & $(0.0116)$ & $(0.0465)$ & $(0.0630)$ \\
\hline \multirow[t]{2}{*}{ Not eating lunch $(-2)$} & -0.00159 & $0.191^{* * *}$ & -0.00408 & -0.0415 & 0.0740 \\
\hline & $(0.0364)$ & $(0.0371)$ & $(0.0103)$ & $(0.0402)$ & $(0.0571)$ \\
\hline \multirow[t]{2}{*}{ Not eating lunch $(-3)$} & $-0.0581^{*}$ & $0.111^{* * *}$ & 0.00909 & -0.0301 & 0.0132 \\
\hline & $(0.0348)$ & $(0.0353)$ & $(0.00885)$ & $(0.0355)$ & $(0.0509)$ \\
\hline \multirow[t]{2}{*}{ Not eating lunch $(-4)$} & 0.00318 & $0.0810^{* * *}$ & -0.0106 & -0.00718 & 0.0219 \\
\hline & $(0.0304)$ & (0.0308) & $(0.00793)$ & $(0.0336)$ & $(0.0441)$ \\
\hline \multirow{2}{*}{ UV $(-1)$} & $-0.0411^{* *}$ & $-0.0628^{* * *}$ & 0.00183 & $0.450^{* * *}$ & $0.0495^{* *}$ \\
\hline & $(0.0185)$ & $(0.0192)$ & $(0.00523)$ & $(0.0248)$ & $(0.0251)$ \\
\hline \multirow[t]{2}{*}{ UV $(-2)$} & 0.00857 & -0.0205 & 0.00640 & $0.164^{* * *}$ & $0.0498^{* *}$ \\
\hline & $(0.0166)$ & $(0.0170)$ & $(0.00521)$ & $(0.0238)$ & $(0.0235)$ \\
\hline \multirow[t]{2}{*}{ UV $(-3)$} & 0.00510 & $-0.0344^{* *}$ & -0.00297 & $0.109^{* * *}$ & $\overline{0}-00320$ \\
\hline & $(0.0155)$ & $(0.0162)$ & $(0.00492)$ & $(0.0223)$ & $(0.0221)$ \\
\hline \multirow[t]{2}{*}{ UV $(-4)$} & -0.0229 & $-0.0358^{* *}$ & -0.00667 & $0.135^{* * *}$ & 0.0333 \\
\hline & $(0.0150)$ & $(0.0157)$ & $(0.00512)$ & $(0.0218)$ & $(0.0205)$ \\
\hline \multirow[t]{2}{*}{ Long sleep $(-1)$} & 0.0658 & $0.173^{*}$ & $0.280^{* * *}$ & 0.118 & -0.144 \\
\hline & $(0.0895)$ & $(0.0899)$ & $(0.0397)$ & $(0.103)$ & $(0.105)$ \\
\hline \multirow[t]{2}{*}{ Long sleep $(-2)$} & 0.0807 & $0.287^{* * *}$ & $0.123^{* * *}$ & 0.0366 & 0.0359 \\
\hline & $(0.0757)$ & (0.0903) & $(0.0345)$ & (0.0959) & $(0.115)$ \\
\hline \multirow[t]{2}{*}{ Long sleep $(-3)$} & $0.172^{* *}$ & $0.228^{* *}$ & $0.142^{* * *}$ & -0.0897 & -0.0899 \\
\hline & $(0.0829)$ & $(0.0901)$ & $(0.0359)$ & $(0.0884)$ & $(0.0909)$ \\
\hline \multirow[t]{2}{*}{ Long sleep (-4) } & 0.0933 & $0.209^{* *}$ & $0.109^{* * *}$ & -0.0217 & 0.0441 \\
\hline & $(0.0830)$ & $(0.0841)$ & $(0.0343)$ & $(0.0900)$ & $(0.107)$ \\
\hline \multirow[t]{2}{*}{ Sitting idly $(-1)$} & -0.00942 & $-0.0551^{* *}$ & -0.000905 & 0.0327 & $0.327^{* * *}$ \\
\hline & $(0.0196)$ & $(0.0215)$ & $(0.00506)$ & $(0.0235)$ & $(0.0518)$ \\
\hline \multirow[t]{2}{*}{ Sitting idly $(-2)$} & -0.00372 & $-0.0298^{*}$ & 0.00194 & 0.0235 & $0.120^{* * *}$ \\
\hline & $(0.0161)$ & $(0.0180)$ & $(0.00466)$ & $(0.0203)$ & $(0.0376)$ \\
\hline \multirow[t]{2}{*}{ Sitting idly $(-3)$} & 0.00581 & $-0.0308^{*}$ & 0.000352 & $0.0320^{*}$ & $0.0962^{* * *}$ \\
\hline & $(0.0151)$ & $(0.0162)$ & $(0.00475)$ & $(0.0186)$ & $(0.0366)$ \\
\hline \multirow[t]{2}{*}{ Sitting idly $(-4)$} & -0.00756 & $-0.0343^{* *}$ & 0.000806 & -0.0228 & $0.0911^{* *}$ \\
\hline & $(0.0137)$ & $(0.0168)$ & $(0.00443)$ & $(0.0194)$ & $(0.0404)$ \\
\hline \multirow{2}{*}{$\begin{array}{l}\text { Seasonal dummy } \\
\text { variable }\end{array}$} & -0.0102 & $-0.0802^{*}$ & 0.0144 & $-0.252^{* * *}$ & 0.0773 \\
\hline & $(0.0402)$ & $(0.0416)$ & $(0.0109)$ & $(0.0488)$ & $(0.0575)$ \\
\hline \multirow{2}{*}{$\begin{array}{l}\text { Pseudo-positive } \\
\text { dummy variable }\end{array}$} & $1.984^{* * *}$ & 0.590 & 0.108 & $-0.493^{* *}$ & 0.283 \\
\hline & $(0.197)$ & $(0.596)$ & $(0.145)$ & $(0.233)$ & $(0.200)$ \\
\hline
\end{tabular}

Number of participants $=87$

Average number of weeks $=44.33$

Lagged dependent variables are included

Standard errors in parentheses. ${ }^{* * *} p<0.01,{ }^{* *} p<0.05,{ }^{*} p<0.1$

compared to other factors because not eating lunch did not have a significant effect on $\mathrm{K} 6$ at the $5 \%$ level.

Results of PVAR indicate that a long sleep in patients aged 50-59 years predicted the recurrence of depression after 4 weeks (Table 6), and a long sleep in the other age groups can predict it after 3 weeks. The estimated coefficient of this week-lagged long sleep was 0.271 (Table 5). This implies that long sleep time increased K6 score 
Table 5 PVAR model II $(N=3023)$

\begin{tabular}{|c|c|c|c|c|c|}
\hline Selected variables & $\begin{array}{l}\text { Natural log of }\{(K 6+1) / \text { square root of the } \\
\text { number of episodes }\}\end{array}$ & $\begin{array}{l}\text { Number of times not eating lunch } \\
\text { (standardized) }\end{array}$ & $\begin{array}{l}\text { Natural log of } \\
\text { UV light }\end{array}$ & $\begin{array}{l}\text { Long } \\
\text { sleep }\end{array}$ & $\begin{array}{l}\text { Sitting } \\
\text { idly }\end{array}$ \\
\hline \multirow[t]{2}{*}{ Not eating lunch $(-1)$} & 0.00237 & $0.295^{* * *}$ & -0.0364 & -0.00678 & 0.0985 \\
\hline & $(0.0462)$ & $(0.0459)$ & $(0.0515)$ & $(0.0124)$ & $(0.0673)$ \\
\hline \multirow[t]{2}{*}{ Not eating lunch $(-2)$} & -0.0225 & $0.167^{* * *}$ & -0.00376 & -0.0165 & 0.0553 \\
\hline & (0.0393) & $(0.0392)$ & $(0.0435)$ & $(0.0107)$ & $(0.0608)$ \\
\hline \multirow[t]{2}{*}{ Not eating lunch $(-3)$} & $-0.0734^{*}$ & $0.0875^{* *}$ & -0.0256 & -0.000261 & 0.00743 \\
\hline & $(0.0378)$ & $(0.0374)$ & $(0.0384)$ & $(0.00932)$ & $(0.0549)$ \\
\hline \multirow[t]{2}{*}{ Not eating lunch $(-4)$} & -0.00421 & $0.0561^{*}$ & -0.0200 & -0.0101 & 0.0209 \\
\hline & $(0.0328)$ & $(0.0325)$ & $(0.0359)$ & $(0.00853)$ & $(0.0458)$ \\
\hline \multirow[t]{2}{*}{ UV $(-1)$} & $-0.0394^{*}$ & $-0.0726^{* * *}$ & $0.421^{* * *}$ & 0.00492 & $0.0631^{* *}$ \\
\hline & $(0.0224)$ & $(0.0238)$ & $(0.0295)$ & $(0.00599)$ & $(0.0289)$ \\
\hline \multirow[t]{2}{*}{ UV $(-2)$} & 0.00750 & -0.0187 & $0.161^{* * *}$ & 0.00253 & 0.0285 \\
\hline & $(0.0200)$ & $(0.0203)$ & $(0.0271)$ & $(0.00584)$ & $(0.0268)$ \\
\hline \multirow[t]{2}{*}{ UV $(-3)$} & 0.00711 & $-0.0440^{* *}$ & $0.116^{* * *}$ & -0.00524 & -0.0106 \\
\hline & $(0.0188)$ & $(0.0196)$ & $(0.0257)$ & $(0.00552)$ & $(0.0252)$ \\
\hline \multirow[t]{2}{*}{ UV $(-4)$} & -0.0181 & $-0.0490^{* *}$ & $0.142^{* * *}$ & -0.00550 & 0.0370 \\
\hline & $(0.0185)$ & $(0.0193)$ & $(0.0249)$ & $(0.00557)$ & $(0.0233)$ \\
\hline \multirow[t]{2}{*}{ Long sleep $(-1)$} & 0.126 & $0.214^{*}$ & 0.152 & $0.239^{* * *}$ & -0.111 \\
\hline & $(0.113)$ & $(0.115)$ & $(0.115)$ & $(0.0461)$ & $(0.134)$ \\
\hline \multirow[t]{2}{*}{ Long sleep $(-2)$} & 0.0804 & $0.266^{* * *}$ & 0.0850 & $0.0823^{* *}$ & 0.0514 \\
\hline & $(0.0904)$ & $(0.102)$ & (0.0958) & $(0.0376)$ & $(0.120)$ \\
\hline \multirow[t]{2}{*}{ Long sleep (-3) } & $0.271^{* * *}$ & $0.351^{* * *}$ & -0.111 & $0.128^{* * *}$ & -0.0567 \\
\hline & (0.0999) & $(0.107)$ & $(0.102)$ & $(0.0417)$ & $(0.113)$ \\
\hline \multirow[t]{2}{*}{ Long sleep (-4) } & 0.104 & $0.282^{* * *}$ & 0.0973 & $0.0614^{*}$ & 0.0433 \\
\hline & $(0.103)$ & $(0.0981)$ & $(0.0964)$ & $(0.0365)$ & $(0.133)$ \\
\hline \multirow[t]{2}{*}{ Sitting idly $(-1)$} & -0.0134 & $-0.0508^{* *}$ & 0.0346 & -0.00207 & $0.357^{* * *}$ \\
\hline & $(0.0211)$ & $(0.0231)$ & $(0.0238)$ & $(0.00530)$ & $(0.0611)$ \\
\hline \multirow[t]{2}{*}{ Sitting idly $(-2)$} & -0.0115 & $-0.0332^{*}$ & 0.0302 & 0.00375 & $0.104^{* *}$ \\
\hline & $(0.0171)$ & $(0.0188)$ & $(0.0207)$ & $(0.00513)$ & $(0.0446)$ \\
\hline \multirow[t]{2}{*}{ Sitting idly $(-3)$} & 0.00236 & -0.0250 & 0.0306 & -0.00170 & $0.114^{* * *}$ \\
\hline & $(0.0159)$ & $(0.0167)$ & $(0.0195)$ & $(0.00441)$ & $(0.0436)$ \\
\hline \multirow[t]{2}{*}{ Sitting idly $(-4)$} & -0.00217 & $-0.0399^{* *}$ & -0.0174 & -0.00554 & $0.0935^{*}$ \\
\hline & $(0.0145)$ & $(0.0176)$ & $(0.0190)$ & $(0.00438)$ & $(0.0493)$ \\
\hline \multirow{2}{*}{$\begin{array}{l}\text { Seasonal dummy } \\
\text { variable }\end{array}$} & 0.00857 & $-0.111^{* *}$ & $-0.246^{* * *}$ & 0.0175 & 0.0604 \\
\hline & $(0.0491)$ & $(0.0513)$ & $(0.0560)$ & $(0.0120)$ & $(0.0649)$ \\
\hline \multirow{2}{*}{$\begin{array}{l}\text { Pseudo-positive } \\
\text { dummy variable }\end{array}$} & $1.969^{* * *}$ & 0.737 & $-0.517^{*}$ & 0.101 & -0.0780 \\
\hline & $(0.227)$ & $(0.721)$ & $(0.311)$ & $(0.154)$ & $(0.230)$ \\
\hline
\end{tabular}

Number of participants $=69$

Average number of weeks $=43.81$

Lagged dependent variables are included

Standard errors in parentheses. ${ }^{* *} p<0.01,{ }^{* *} p<0.05,{ }^{*} p<0.1$

from 5 to 6.86 after 3 weeks. Lagged long sleep also contributed to increase in the number of times lunch was not eaten in the present week. Table 6 shows that the estimated coefficient of 4-week lagged long sleep was 0.191, which was smaller than 0.271 above. Lagged long sleep in those aged $50-59$ years had smaller effects on K6 scores this week, compared to the other age groups. Moreover, 4-week lagged UV light exposure had a decreasing effect on K6 this week. 
Table 6 PVAR model III $(N=834)$

\begin{tabular}{|c|c|c|c|c|c|}
\hline Selected variables & $\begin{array}{l}\text { Natural log of }\{(K 6+1) / \text { square root of the } \\
\text { number of episodes }\}\end{array}$ & $\begin{array}{l}\text { Number of times not eating lunch } \\
\text { (standardized) }\end{array}$ & $\begin{array}{l}\text { Natural log of } \\
\text { UV light }\end{array}$ & $\begin{array}{l}\text { Long } \\
\text { sleep }\end{array}$ & $\begin{array}{l}\text { Sitting } \\
\text { idly }\end{array}$ \\
\hline \multirow[t]{2}{*}{ Not eating lunch $(-1)$} & -0.0535 & $0.302^{* * *}$ & -0.00145 & -0.000906 & -0.0169 \\
\hline & $(0.0709)$ & $(0.0940)$ & $(0.0676)$ & $(0.0167)$ & $(0.0930)$ \\
\hline \multirow[t]{2}{*}{ Not eating lunch $(-2)$} & 0.00318 & $0.152^{*}$ & $-0.172^{* *}$ & 0.0294 & 0.140 \\
\hline & $(0.0602)$ & $(0.0913)$ & $(0.0732)$ & $(0.0231)$ & $(0.0913)$ \\
\hline \multirow[t]{2}{*}{ Not eating lunch $(-3)$} & -0.0583 & 0.0996 & -0.0358 & $0.0304^{*}$ & 0.0537 \\
\hline & $(0.0635)$ & $(0.0912)$ & $(0.0680)$ & $(0.0180)$ & $(0.0823)$ \\
\hline \multirow[t]{2}{*}{ Not eating lunch $(-4)$} & -0.152 & 0.0673 & -0.0545 & $-0.0457^{* *}$ & -0.0129 \\
\hline & $(0.135)$ & $(0.0816)$ & $(0.107)$ & $(0.0216)$ & $(0.162)$ \\
\hline \multirow[t]{2}{*}{ UV $(-1)$} & -0.0632 & -0.0265 & $0.523^{* * *}$ & -0.00834 & -0.0544 \\
\hline & $(0.0441)$ & $(0.0376)$ & $(0.0578)$ & $(0.0113)$ & $(0.0574)$ \\
\hline \multirow[t]{2}{*}{ UV $(-2)$} & -0.00312 & -0.0180 & $0.127^{* *}$ & 0.0195 & $0.125^{* *}$ \\
\hline & $(0.0391)$ & $(0.0333)$ & $(0.0599)$ & $(0.0119)$ & $(0.0571)$ \\
\hline \multirow[t]{2}{*}{ UV $(-3)$} & -0.000449 & -0.000159 & 0.0436 & -0.00159 & 0.0194 \\
\hline & $(0.0279)$ & $(0.0330)$ & $(0.0432)$ & $(0.0111)$ & $(0.0517)$ \\
\hline \multirow[t]{2}{*}{ UV $(-4)$} & $-0.0529^{* *}$ & -0.00642 & $0.130^{* * *}$ & -0.0102 & 0.00285 \\
\hline & $(0.0240)$ & $(0.0299)$ & $(0.0481)$ & $(0.0107)$ & $(0.0476)$ \\
\hline \multirow[t]{2}{*}{ Long sleep $(-1)$} & -0.0295 & 0.0491 & 0.0586 & $0.344^{* * *}$ & -0.183 \\
\hline & $(0.108)$ & $(0.124)$ & $(0.173)$ & $(0.0732)$ & $(0.157)$ \\
\hline \multirow[t]{2}{*}{ Long sleep $(-2)$} & 0.204 & 0.211 & -0.0162 & $0.208^{* * *}$ & 0.0810 \\
\hline & $(0.128)$ & $(0.130)$ & $(0.181)$ & $(0.0687)$ & $(0.220)$ \\
\hline \multirow[t]{2}{*}{ Long sleep (-3) } & -0.0191 & -0.0858 & 0.127 & $0.117^{*}$ & -0.173 \\
\hline & $(0.130)$ & $(0.141)$ & $(0.140)$ & (0.0698) & $(0.133)$ \\
\hline \multirow[t]{2}{*}{ Long sleep (-4) } & $0.191^{*}$ & -0.0327 & -0.218 & $0.203^{* * *}$ & 0.0697 \\
\hline & $(0.105)$ & $(0.126)$ & $(0.175)$ & $(0.0756)$ & $(0.149)$ \\
\hline \multirow[t]{2}{*}{ Sitting idly $(-1)$} & 0.0317 & -0.0107 & 0.0145 & 0.0121 & $0.165^{* * *}$ \\
\hline & $(0.0350)$ & $(0.0409)$ & $(0.0543)$ & $(0.0140)$ & $(0.0603)$ \\
\hline \multirow[t]{2}{*}{ Sitting idly $(-2)$} & -0.00850 & 0.0431 & -0.0792 & -0.0134 & 0.159 \\
\hline & $(0.0862)$ & $(0.0464)$ & $(0.0816)$ & $(0.0167)$ & $(0.110)$ \\
\hline \multirow[t]{2}{*}{ Sitting idly $(-3)$} & -0.00393 & 0.00114 & -0.00544 & 0.00122 & 0.000576 \\
\hline & $(0.0516)$ & $(0.0399)$ & $(0.0533)$ & $(0.0133)$ & $(0.0645)$ \\
\hline \multirow[t]{2}{*}{ Sitting idly $(-4)$} & -0.00854 & 0.0300 & -0.0495 & $0.0234^{*}$ & 0.0202 \\
\hline & $(0.0285)$ & $(0.0395)$ & $(0.0455)$ & $(0.0130)$ & $(0.0535)$ \\
\hline \multirow{2}{*}{$\begin{array}{l}\text { Seasonal dummy } \\
\text { variable }\end{array}$} & $-0.126^{* *}$ & 0.0424 & $-0.270^{* * *}$ & -0.00152 & 0.142 \\
\hline & $(0.0633)$ & $(0.0875)$ & $(0.0992)$ & $(0.0157)$ & $(0.107)$ \\
\hline \multirow{2}{*}{$\begin{array}{l}\text { Pseudo-positive } \\
\text { dummy variable }\end{array}$} & 12.66 & -3.844 & 15.84 & 3.057 & -5.221 \\
\hline & $(21.12)$ & $(14.26)$ & (13.99) & $(2.974)$ & $(22.97)$ \\
\hline
\end{tabular}

Number of participants $=18$

Average number of weeks $=46.33$

Lagged dependent variables are included

Standard errors in parentheses. ${ }^{* *} p<0.01,{ }^{* *} p<0.05,{ }^{*} p<0.1$

\section{Discussion}

The main findings of the present study were as follows. A PVAR analysis indicated that long sleep predicted the recurrence of depression after 3 weeks. Long sleep in patients aged 50-59 years predicted the recurrence of depression after 4 weeks, and long sleep in the other age groups predicted recurrence after 3 weeks.

Sleep disturbance is one of the diagnostic symptoms of major depression and is closely associated with depression, mainly in the form of insomnia (approximately 
$75 \%$ ) and less often in the form of hypersomnia (approximately $10 \%$ ) [24]. It is one of the most common residual symptoms of depression [25], which has been repeatedly found to constitute greater risk for subsequent depression recurrence [26, 27]. While it is usually residual insomnia that has been found to constitute a risk factor [28], some studies did find hypersomnia to be a risk factor as well [29]. In either case, however, they are sleep disturbance measured with an observer-rated or self-rated symptom inventory and therefore covering the past one or two weeks, our study was unique in measuring daily change in sleep hours and singling out long sleep, rather than short sleep, 3-4 weeks prior to depression aggravation.

Not eating lunch regularly, sitting idly and UV exposure (as a measure of outings) were candidate variables to predict depression relapse/recurrence. However, when taken together with long sleep, they were no longer predictive. The non-significant nature of their contributions may be due to low statistical power of the current sample $(n=89)$, and their joint predictive capabilities merit further investigation in a larger sample in the future. The current explanatory feasibility study has established that such a study is possible.

This study has important features. First, using the Kurashi-app, we were able to collect lifelog data from 89 patients for 1 year. While it is difficult for researchers to analyse sleep habits using conventional pen and paper methods, accurate information about sleep habits over longer sample periods allows for an easier empirical analysis. In general, sleep-diary data tend to be subjective daily reports of sleep from 1 to 2 weeks [30], which are data from shorter sample periods than the current data. Because the Kurashi-app extracts clusters of activities every $30 \mathrm{~min}$, we were able to record a variety of activities such as sitting idly. From the viewpoint of the accuracy of activity records, our data of detailed activities, based on semi-automated recordings, corrected by the participants under close central monitoring, were superior to data of conventional studies that used several variants of Life Chart Method to examine mood course over longer periods of time (see, [31]).

Secondly, we used two screening tools for depression. By using both K6 and PHQ-9, we imputed the missing K6 data. Missing UV light exposure data were also imputed. We were able to define a pseudo-positive dummy variable as a false alarm of recurrence of depression, and used it to analyse the increase in K6 and PHQ-9 scores, although this increase was not necessarily indicative of a full depression recurrence above the diagnostic threshold.

Thirdly, we identified predictors of the deterioration of mental health status quantitatively through the estimation of PVAR models. Our panel VAR model was not liable to lead to seriously biased coefficients, compared to standard panel data methods such as fixed-effects model or random-effects model. This is a strength of our approach. Previous studies pointed out efficacy of early intervention aimed at preventing relapse or recurrence among high risk populations [32, 33]; however, no prior studies have established a method for identifying the signs of recurrence. If one could detect the signs of depression recurrence and perform a cognitive behavioural therapy intervention in a timely manner, the deterioration of mental health status could be minimised.

On the other hand, the study has some limitations. First, we did not restrict on medication and psychotherapy, and therapists could change their treatment depending on the situation. It might have influenced the relapse. However, our intention was to capture the approaching relapse even in such circumstances. Secondly, any prediction model require replication for extensive validation; however, we did not have a big enough sample size to ascertain external validity. We need future studies to examine replication of our findings. Third, the relapse/recurrence was defined by self-reports on K6. Finally, the convenient sampling of the present cohort may limit our ability to generalise findings from this study.

\section{Conclusion}

We found that long sleep time was a risk factor for the recurrence of depression three to four weeks later. The PVAR approach using lifelog data could contribute to establishing a method for identifying the warning signs of recurrence in patients in remission of major depression. Future research could focus on identifying the predictors of long sleep time, which was one of the dependent variables in the PVAR model in the current study.

\section{Supplementary information}

Supplementary information accompanies this paper at https://doi.org/10. 1186/s12888-019-2382-2.

Additional file 1. Investigators and committee members.

\section{Abbreviations}

K6: Kessler Psychological Distress Scale; PHQ-9: Patient Health Questionnaire9; PVAR: Panel Vector Autoregressive

\section{Acknowledgements}

We are grateful for the helpful comments of Professor Hideki Hashimoto. Group information: A complete list of participating centers and investigators is provided in Additional file 1.

\section{Authors' contributions}

AT, AH, NK1 and TAF had full access to all the data in the study and take responsibility for the integrity of the data and the accuracy of the data analysis. Study concept and design: AT, AH, NK2 and TAF. Acquisition, analysis, or interpretation of data: SS, KK and BC. Drafting of the manuscript: NK1. Critical revision of the manuscript for important intellectual content: AT AH and TAF. Statistical analysis: NK1. Administrative, technical, or material support: AH and NK2. Study supervision: MH and TAF. All authors read and approved the final manuscript. 


\section{Funding}

The study was funded by National Institute of Information and Communications Technology (NICT), Japan (178A05) from April 2014 through March 2018. This research results have been obtained by "Research and Development on Fundamental and Utilization Technologies for Social Big Data," Commissioned Research of National Institute of Information and Communications Technology (NICT), JAPAN. The first author would also like to express his appreciation for the financial support from Japan's Ministry of Education, Culture, Sports, Science, and Technology (Grant No. 15 K03528). The funder of the study had no role in study design, data collection, data analysis, data interpretation or in writing of the report.

\section{Availability of data and materials}

The datasets generated and/or analyzed during the current study are not publicly available due the Japanese clinical research ethics guidelines but are available from the corresponding author on reasonable request and after approval of the planned analyses by the ethics committee at Kyoto University Graduate School of Medicine as per the Japanese ethics guidelines.

\section{Ethics approval and consent to participate}

The study protocol was approved by the ethics committees/institutional review boards of Kyoto University Graduate School of Medicine (R0591-6), Nagoya City University Hospital (50-16-0001), Kochi Medical School (28-67), Hiroshima University Hospital (C-105-3), Toho University School of Medicine (A17062). All participants provided written informed consent.

\section{Consent for publication}

Not applicable.

\section{Competing interests}

SS has received lecture fees from Otsuka, MSD, Meiji, Eli Lilly, Mochida and Shionogi. KK has received lecture fees from Meiji. TAF has received lecture fees from Meiji, Mitsubishi-Tanabe, MSD and Pfizer. He has received research support from Mitsubishi-Tanabe. All the other authors declare that they have no competing interests.

\section{Author details}

'Department of Economics, Seinan Gakuin University, 6-2-92, Nishijin, Sawara-ku, Fukuoka 814-8511, Japan. ²Department of Psychiatry, Kyoto University Hospital, 54 Shogoin-Kawahara-cho, Sakyo-ku, Kyoto 606-8507, Japan. ${ }^{3}$ Advanced Telecommunications Research Institute International, 2-2-2 Hikaridai, Seika-cho, Soraku-gun, Kyoto 619-0288, Japan. ${ }^{4}$ Sonas Inc., 6F, Grace Imas Building, 5-24-2, Hongo, Bunkyo-ku, Tokyo 113-0033, Japan. ${ }^{5}$ National Center for Cognitive Behavior Therapy and Research, National Center of Neurology and Psychiatry, 4-1-1 Ogawahigashi-cho, Kodaira, Tokyo 187-8553, Japan. ${ }^{6}$ Ginza Shimodera Clinic, 8B-6-9-6 Ginza Chuo Ward, Tokyo 104-0061, Japan. ${ }^{7}$ Department of Health Promotion and Human Behavior, Kyoto University Graduate School of Medicine / School of Public Health, Yoshida Konoe-cho, Sakyo-ku, Kyoto 606-8501, Japan. ${ }^{8}$ Kabe Mental Health Clinic, 4-6-2 Kabe, Asakita-ku, Hiroshima 731-0221, Japan. ${ }^{9}$ Ginza Taimei Clinic, 5-1-15 Ginza, Chuou-ku, Tokyo 104-0061, Japan.

\section{Received: 22 April 2019 Accepted: 29 November 2019}

\section{Published online: 11 December 2019}

\section{References}

1. Kessler RC, Bromet EJ. The epidemiology of depression across cultures. Annu Rev Public Health. 2013;34:119-38.

2. Alexopoulos GS, Meyers BS, Young RC, Kalayam B, et al. Executive dysfunction and long-term outcomes of geriatric depression. Arch Gen Psychiatry. 2000;57(3):285-90.

3. Alexopoulos GS, Young RC, Abrams RC, Meyers B, Shamoian CA. Chronicity and relapse in geriatric depression. Biol Psychiatry. 1989;26:551-64.

4. Deng $Y$, McQuoid DR, Potter GG, Steffens DC, et al. Predictors of recurrence in remitted late-life depression. Depress Anxiety. 2018;35(7):658-67.

5. Gueorguieva R, Chekroud AM, Krystal JH. Trajectories of relapse in randomised, placebo-controlled trials of treatment discontinuation in major depressive disorder: an individual patient-level data meta-analysis. Lancet Psychiatry. 2017:4:230-7.
6. Solomon DA, Leon AC, Endicott J, Mueller TI, et al. Psychosocial impairment and recurrence of major depression. Compr Psychiatry. 2004;45:423-30.

7. Velten J, Bieda A, Scholten S, Wannemüller A, et al. Lifestyle choices and mental health: a longitudinal survey with German and Chinese students. BMC Public Health. 2018;18:632.

8. Andreescu C, Lenze EJ, Dew MA, Begley AE. Effect of comorbid anxiety on treatment response and relapse risk in late-life depression: controlled study. Br J Psychiatry. 2007;190:344-9.

9. Klein NS, Holtman GA, Bockting CLH, Heymans MW, et al. Development and validation of a clinical prediction tool to estimate the individual risk of depressive relapse or recurrence in individuals with recurrent depression. J Psychiatr Res. 2018;104:1-7.

10. ten Have M, de Graaf R, van Dorsselaer S, Tuitho M, et al. Recurrence and chronicity of major depressive disorder and their risk indicators in a population cohort. Acta Psychiatr Scand. 2018;137(6)503-15.

11. Reynolds CFIII, Dew MA, Pollock BG, Mulsant BH, et al. Maintenance treatment of major depression in old age. N Engl J Med. 2006;354:1130-8.

12. Sarris J, O'Neil A, Coulson CE, Schweitzer I, et al. Lifestyle medicine for depression. BMC Psychiatry. 2014;14:107.

13. Kawanishi N, Tajika A, Tamai M, Ogawa Y, et al. LifeLog-based Estimation of Activity Diary for Cognitive Behavioral Therapy. Adjunct Proceedings of the 2015 ACM International Joint Conference on Pervasive and Ubiquitous Computing and Proceedings of the 2015 ACM International Symposium on Wearable Computers. 2015. https://dl.acm.org/citation.cfm?id=2807939.

14. Hiroe T, Kojima M, Yamamoto I, et al. Gradations of clinical severity and sensitivity to change assessed with the Beck depression inventory-II in Japanese patients with depression. Psychiatry Res. 2005;135:229-35.

15. Kessler RC, Andrews G, Colpe LJ, et al. Short screening scales to monitor population prevalences and trends in non-specific psychological distress. Psychol Med. 2002;32(6):959-76.

16. Prochaska JJ, Sung HY, Max W, Shi Y, et al. Validity study of the K6 scale as a measure of moderate mental distress based on mental health treatment need and utilization. Int J Methods Psychiatr Res. 2012;21(2):88-97.

17. Arnaud B, Malet $L$, Teissedre $F$, Izaute $M$, et al. Validity study of Kessler's psychological distress scales conducted among patients admitted to French emergency Department for Alcohol Consumption? Related disorders. Alcohol Clin Exp Res. 2010;34(7):1235-45.

18. Tomitaka $S$, Kawasaki $Y$, Ide K, Akutagawa M, et al. Distributional patterns of item responses and total scores on the PHQ-9 in the general population: data from the National Health and nutrition examination survey. BMC Psychiatry. 2018;18:108.

19. Cheng L, Evanston IL. Little's test of missing completely at random. Stata J. 2013:13(4):795-809.

20. National Statistics Center. A Study on the Imputation of Missing Data in Official Statistics: Multiple Imputation and Single Imputation. 2015.

21. King G, Honaker J, Joseph A, Scheve K. Analyzing incomplete political science data: an alternative algorithm for multiple imputation. Am Polit Sci Rev. 2001;95(1):49-69.

22. Nickell S. Biases in dynamic models with fixed effects. Econometrica. 1981; 49(6):1417-26

23. Michael-Abrigo RM, Love I. Estimation of panel vector autoregression in Stata. Stata J. 2016;16(3):778-804.

24. Nutt D, Wilson S, Paterson L. Sleep disorders as core symptoms of depression. Dialogues Clin Neurosci. 2008;10(3):329-36.

25. Carney CE, Segal ZV, Edinger JD, Krystal AD. A comparison of rates of residual insomnia symptoms following pharmacotherapy or cognitive-behavioral therapy for major depressive disorder. J Clin Psychiatry. 2007:68:254-60.

26. Judd LL, Akiskal HS, Maser JD, Zeller PJ, Endicott J, Coryell W, Paulus MP, Kunovac JL, Leon AC, Mueller TI, Rice JA, Keller MB. Major depressive disorder: a prospective study of residual subthreshold depressive symptoms as predictor of rapid relapse. J Affect Disord. 1998;50:97-108.

27. Perlis ML, Giles DE, Buysse DJ, Tu X, Kupfer DJ. Self-reported sleep disturbance as a prodromal symptom in recurrent depression. J Affect Disord. 1997:42:209-12.

28. Nierenberg AA, Husain MM, Trivedi MH, Fava M, Warden D, Wisniewski SR, Miyahara S, Rush AJ. Residual symptoms after remission of major depressive disorder with citalopram and risk of relapse: a STAR*D report. Psychol Med. 2010:40:41-50.

29. Sakurai H, Suzuki T, Yoshimura K, Mimura M, Uchida H. Predicting relapse with individual residual symptoms in major depressive disorder: a reanalysis of the STAR*D data. Psychopharmacology. 2017;234:2453-61. 
30. Buysse DJ, Ancoli-Israel S, Edinger JD, Lichstein KL, et al. Recommendations for a standard research assessment of insomnia. Sleep. 2006;29(9):1155-73.

31. Koenders MA, Nolen WA, Giltay EJ, Hoencamp E, et al. The use of the prospective NIMH Life Chart Method as a bipolar mood assessment method in research: A systematic review of different methods, outcome measures and interpretations. J Affect Disord. 2015;175:260-8.

32. Narushima K, Robinson RG. The effect of early versus late antidepressant treatment on physical impairment associated with Poststroke depression. Is there a time-related therapeutic window? J Nerv Ment Dis. 2003;191(10): 645-52.

33. Sim K, Lau WK, Sim J, Sum MY, et al. Prevention of relapse and recurrence in adults with major depressive disorder: systematic review and metaanalyses of controlled trials. Int J Neuropsychopharmacol. 2015;19(2). https://doi.org/10.1093/ijnp/pyv076.

\section{Publisher's Note}

Springer Nature remains neutral with regard to jurisdictional claims in published maps and institutional affiliations.

Ready to submit your research? Choose BMC and benefit from:

- fast, convenient online submission

- thorough peer review by experienced researchers in your field

- rapid publication on acceptance

- support for research data, including large and complex data types

- gold Open Access which fosters wider collaboration and increased citations

- maximum visibility for your research: over $100 \mathrm{M}$ website views per year

At BMC, research is always in progress.

Learn more biomedcentral.com/submissions 